\title{
Demographics, Usage Patterns, and Safety of Male Users of Clomiphene in the United States
}

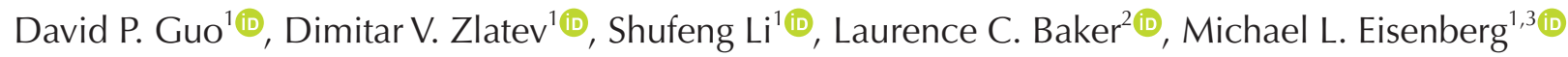 \\ ${ }^{1}$ Department of Urology, Stanford University School of Medicine, ${ }^{2}$ Department of Health Research and Policy, Stanford University, \\ ${ }^{3}$ Department of Obstetrics and Gynecology, Stanford University School of Medicine, Stanford, CA, USA
}

\begin{abstract}
Purpose: The aim of this study was to characterize the demographics, usage patterns and complication rates of clomiphene use in male patients.

Materials and Methods: We retrospectively analyzed male patients from ages 20 to 55 years old who were prescribed clomiphene citrate from 2001 to 2014 using the Truven Health MarketScan, a US claims database. We collected data regarding associated medical diagnoses, diagnostic testing, duration of use, and reported side effects including thrombotic events, vision problems, gynecomastia, mental disorders, liver disease, nausea, or skin problems.

Results: In total, 12,318 men took clomiphene and represented the primary study cohort, with a mean age of 37.8 years. The percentage of men prescribed clomiphene increased over the study period, as did the average age of clomiphene users. Associated diagnoses included male infertility $(52.0 \%)$, testicular hypofunction $(13.5 \%)$, erectile dysfunction $(2.4 \%)$, and low libido (0.4\%). Associated testing included semen analysis (43.7\%), testosterone (23.5\%), luteinizing hormone $(19.3 \%)$, and follicle-stimulating hormone (21.1\%) levels. The median time of clomiphene use was 3.6 months, with $63 \%$ of men stopping within 6 months. No increased risk of reported clomiphene side effects were apparent in men taking the medication.

Conclusions: There is a rising prevalence of clomiphene usage without associated adverse side effects in the US. The variability in associated diagnoses, diagnostic testing, and duration of use suggest a need for greater awareness of the proper evaluation and treatment of the men who are prescribed clomiphene.
\end{abstract}

Keywords: Clomiphene; Demography; Infertility, male; Safety

This is an Open Access article distributed under the terms of the Creative Commons Attribution Non-Commercial License (http://creativecommons.org/licenses/by-nc/4.0) which permits unrestricted non-commercial use, distribution, and reproduction in any medium, provided the original work is properly cited.

\section{INTRODUCTION}

Infertility affects $15 \%$ of all couples in the US, and nearly half of these instances involve a male factor [1]. There are no oral medications for the treatment of male infertility that are approved by the US Food and Drug Administration (FDA). Clomiphene citrate was first introduced in the 1960s as an FDA-approved med- ication for the treatment of female infertility, however has been also used off-label since the 1970s for male infertility [2].

Clomiphene is a selective estrogen receptor modulator that blocks negative feedback to the hypothalamus, thereby inducing increased release of gonadotropin from the pituitary. In females, this leads to increased ovulation. In males, the mechanism of action of clomi-

Received: Feb 14, 2019 Revised: May 27, 2019 Accepted: Jun 16, 2019 Published online Jul 12, 2019

Correspondence to: Michael L. Eisenberg (iD https://orcid.org/0000-0001-5482-0141

Department of Urology, Stanford Hospital and Clinics, Grant S-287, 300 Pasteur Road Stanford, CA, 94305, USA.

Tel: +1-650-497-8753, Fax: +1-650-498-5346, E-mail: eisenberg@stanford.edu 
phene may lead to increased testosterone generation and spermatogenesis [3,4] and this has led to its offlabel use for both male hypogonadism and infertility.

The literature regarding the efficacy of clomiphene use in men has been mixed. A multicenter randomized controlled trial (RCT) sponsored by the World Health Organization involving 190 males in the 1980s and 1990s demonstrated no statistically significant changes in semen parameters or pregnancies after 6 months of clomiphene usage [5]. Conversely, a more recent RCT involving 60 males with idiopathic infertility found that after 6 months of clomiphene with vitamin $\mathrm{E}$ usage there were statistically improved sperm concentration and pregnancy rates [6]. Additionally, a recent meta-analysis suggested improved pregnancy rates with clomiphene use [7]. However, while the adverse side effects of clomiphene use have been well documented in women [4], the literature on safety in men has been scant.

Despite the lack of consensus in regards to its efficacy and safety, a survey of the membership of the American Urological Association in 2012 revealed that $90 \%$ of urologists offered clomiphene to infertile male patients [8]. However, although it is widely accepted in the US, the literature regarding the usage of clomiphene is sparse. We sought to characterize the demographics, usage patterns, and safety of clomiphene in men across the US.

\section{MATERIALS AND METHODS}

\section{Ethics statement}

The study protocol was approved by the Institutional Review Board (IRB) of Stanford University (IRB\# 35751).

Informed consent was not necessary given use of a deidentified and HIPAA (Health Insurance Portability and Accountability Act) compliant database.

\section{Subject}

The IBM (formerly Truven) MarketScan Commercial Claims and Encounters Database was used to identify eligible patients. This database provides information from adjudicated and paid insurance claims filed for the care of privately insured individuals with employment based insurance through a participating employer. MarketScan provides claims data on over 77 million covered individuals since 1996. The number of partici- pants represented in the database varies over time, however recent years have contained approximately 30 million individuals.

Pharmacy claims from 2001 to 2014 were utilized to assemble the cohort of male enrollees between the ages of 20 and 55 who received a prescription of clomiphene citrate. This age range was selected as clomiphene is used most commonly during the reproductive years. To assess temporal trends, we used the entire dataset. To assess current prescription patterns, associated diagnoses, and outcomes, we examined the cohort from 2007 to 2014. The number of refills and dates of prescriptions were used to assess the duration of use. The associated diagnoses and treatments received by these men were identified by utilizing International Classification of Diseases, 9th edition (ICD-9) and Current Procedural Terminology (CPT) codes. Specifically, we identified patients with diagnoses of male infertility (606.x, V26.21), testicular hypofunction (257.2), erectile dysfunction (302.72, 607.84), and low libido (799.81).

Laboratory testing was identified using CPT codes, specifically semen testing and semen preparation (89300, 89310, 89320, 89321, 89322, 89325, 89329, 89330, 89331), Testosterone (84402, 84403), Luteinizing Hormone (LH) (83002), and Follicle-stimulating Hormone (FSH) (83001).

Adverse effects were identified using ICD-9 codes. These included eye problems (360-379), deep venous thrombosis (453), gynecomastia (611), depression (290319), liver damage (570-573), nausea (787), skin disorders (680-709), hypertension (401-405), ischemic heart disease or myocardial infarction (410-414), cardiac dysrhythmias (426-427), and malignancy (140-209) based on associated side effects reported for clomiphene. Due to the limitations of claims data, these outcome codes were left intentionally broad.

To assess for the risk of side effects with clomiphene use, we compared the incidence of these side effects 6 months before use versus 6 months after use of clomiphene. All p-values were two sided and $p<0.05$ was considered statistically significant. Analyses were performed using SAS ver. 9.3 (SAS Institute, Inc., Cary, NC, USA).

\section{RESULTS}

Over the duration of the study period, the prevalence of clomiphene use approximately doubled, from $0.016 \%$ 
Table 1. Prevalence and average age of male users of clomiphene in the US

\begin{tabular}{cccc}
\hline Year & $\begin{array}{c}\text { Male clomiphene } \\
\text { user }(\mathrm{n})\end{array}$ & $\begin{array}{c}\text { Percentage of all } \\
\text { male enrollee }(\%)\end{array}$ & $\begin{array}{c}\text { Mean } \\
\text { age }(\mathbf{y})\end{array}$ \\
\hline 2001 & 176 & 0.016 & 34.3 \\
2002 & 252 & 0.010 & 35.3 \\
2003 & 316 & 0.009 & 35.8 \\
2004 & 443 & 0.009 & 35.6 \\
2005 & 449 & 0.009 & 35.9 \\
2006 & 522 & 0.007 & 36.2 \\
2007 & 568 & 0.007 & 35.9 \\
2008 & 1,144 & 0.001 & 36.6 \\
2009 & 1,449 & 0.001 & 36.9 \\
2010 & 1,761 & 0.014 & 37.3 \\
2011 & 2,489 & 0.018 & 37.8 \\
2012 & 3,302 & 0.023 & 38.0 \\
2013 & 3,947 & 0.036 & 38.2 \\
2014 & 5,175 & 0.042 & 38.6 \\
\hline
\end{tabular}

This table demonstrates the rise in clomiphene usage and mean age of clomiphene users between 2001 and 2014.

in 2001 to $0.042 \%$ in 2014 . The mean age of men taking clomiphene also increased from 34.3 years in 2001 to 38.6 years in 2014 (Table 1).

The primary study cohort, consisting of individuals with data on associated diagnoses and testing from 2007 to 2014, contained 12,318 men with a mean age of 37.8 years. When stratified by age group, $50 \%$ of men who took clomiphene were 30 to 39 years old and another $30 \%$ of men were 40 to 49 years old. The median duration of clomiphene use was 3.6 months. The majority of men (63.2\%) used clomiphene under 6 months; another $18.5 \%$ stopped in 6 to 12 months, $7.5 \%$ stopped in 12 to 18 months, and $4.2 \%$ stopped in 18 to 24 months. Only $6.5 \%$ of clomiphene users continued beyond 24 months (Table 2). The median monthly copay was $\$ 20$ for a prescription of clomiphene (range, $\$ 0-\$ 1,862)$.

The most commonly associated diagnoses of men taking clomiphene were male infertility or fertility testing (52.0\%), testicular hypofunction (13.5\%), erectile dysfunction (2.4\%), and low libido (0.4\%). The most common tests performed for men taking clomiphene were semen analysis (43.7\%), testosterone level (23.5\%), LH (19.3\%), and FSH (21.1\%) (Table 3).

Only men with adequate follow-up were included in the analysis of complication rates $(n=5,118)$. The rates of side effects that occurred within 6 months of clomiphene initiation were very low. Specifically,
Table 2. Duration of clomiphene use in study cohort

\begin{tabular}{ccc}
\hline $\begin{array}{c}\text { Duration of } \\
\text { clomiphene use (mo) }\end{array}$ & No. of males & $\begin{array}{c}\text { Percentage } \\
\text { of cohort (\%) }\end{array}$ \\
\hline $0-6$ & 7,791 & 63.2 \\
$6-12$ & 2,280 & 18.5 \\
$12-18$ & 923 & 7.5 \\
$18-24$ & 519 & 4.2 \\
Over 24 & 805 & 6.5 \\
\hline
\end{tabular}

The majority of male patients (81.7\%) used clomiphene for under 12 months.

Table 3. Associated diagnosis codes and testing in study cohort

\begin{tabular}{lcc}
\multicolumn{1}{c}{ Variable } & No. of males & $\begin{array}{c}\text { Percentage } \\
\text { of total (\%) }\end{array}$ \\
\hline Associated diagnosis code ${ }^{\mathrm{a}}$ & & \\
$\quad$ Male infertility & 6,401 & 52.0 \\
Testicular hypofunction & 1,659 & 13.5 \\
Erectile dysfunction & 300 & 2.4 \\
Low libido & 50 & 0.4 \\
Associated diagnostic testing & & \\
Semen analysis & 5,377 & 43.7 \\
Testosterone & 2,900 & 23.5 \\
Luteinizing hormone & 2,381 & 19.3 \\
Follicle stimulating hormone & 2,593 & 21.1 \\
\hline
\end{tabular}

${ }^{2}$ The most frequent diagnosis codes associated with clomiphene use are male infertility and testicular hypofunction. ${ }^{\mathrm{b}}$ The most frequent diagnostic testing associated with clomiphene use are semen analysis and testosterone measurement.

no increased risk of reported clomiphene side effects (thrombotic events, vision problems, liver disease, nausea) were apparent in men taking the medication at 6 months after onset of medication usage versus 6 months prior to starting the medication. A lower rate of gynecomastia, mental disorders, skin disorders, and hypertension were identified after clomiphene use versus before (Table 4).

\section{DISCUSSION}

This study shows that the prevalence of clomiphene use has increased over the past 15 years, with male infertility and testicular hypofunction as the most common associated diagnoses. Most men also receive relevant testing, including semen analysis and hormonal function tests. Importantly, there is no increased risk of side effects within 6 months of clomiphene use in this contemporary cohort.

This study demonstrates that clomiphene use has 
Table 4. Complication events at 6 months before and after clomiphene use

\begin{tabular}{|c|c|c|c|c|c|}
\hline Complication & Number (\%) & $\begin{array}{c}\text { No. event }(\%) \\
6 \text { months before clomid }\end{array}$ & $\begin{array}{c}\text { No. event }(\%) \\
6 \text { months after clomid }\end{array}$ & $\begin{array}{l}\text { Relative risk after vs. } \\
\text { before clomid }^{\mathrm{a}}\end{array}$ & $\mathrm{p}$-value \\
\hline Eye disorders & $1,759(34.37)$ & $165(3.22)$ & $138(2.70)$ & $0.84(0.67-1.05)$ & 0.1346 \\
\hline Deep vein thrombosis & $99(1.93)$ & $9(0.18)$ & $12(0.23)$ & $1.33(0.56-3.16)$ & 0.5138 \\
\hline Gynecomastia & $161(3.15)$ & $33(0.64)$ & $13(0.25)$ & $0.39(0.21-0.75)$ & 0.0044 \\
\hline Mental disorders & $2,344(45.80)$ & $294(5.74)$ & $170(3.32)$ & $0.58(0.48-0.70)$ & $<0.0001$ \\
\hline Liver disease & $463(9.05)$ & $61(1.19)$ & $40(0.78)$ & $0.68(0.45-1.01)$ & 0.057 \\
\hline Nausea & $1,176(22.98)$ & $109(2.13)$ & $123(2.40)$ & $1.15(0.89-1.49)$ & 0.2806 \\
\hline Skin disorders & $2,836(55.41)$ & $272(5.31)$ & $210(4.10)$ & $0.78(0.65-0.93)$ & 0.0056 \\
\hline Hypertension & $1,800(35.17)$ & $197(3.85)$ & $110(2.15)$ & $0.56(0.45-0.71)$ & $<0.0001$ \\
\hline Ischemic heart disease & $318(6.21)$ & $35(0.68)$ & $32(0.63)$ & $0.91(0.56-1.47)$ & 0.7023 \\
\hline Cardiac dysrhythmias & $458(8.95)$ & $50(0.98)$ & $33(0.64)$ & $0.66(0.43-1.02)$ & 0.0629 \\
\hline All malignancy & $352(6.88)$ & $36(0.70)$ & $31(0.61)$ & $0.86(0.53-1.39)$ & 0.5414 \\
\hline
\end{tabular}

There was no increase in deep vein thrombosis, ischemic heart disease, or liver disease in the 6 months following clomiphene administration. Conversely, there was a decrease in gynecomastia, mental disorders, skin disorders, and hypertension in the 6 months following clomiphene administration.

${ }^{a}$ Values are presented as median (range).

matched some of the recent trends in male infertility evaluation. For instance, the average age of the clomiphene user has risen from 34 years in 2001 to 38 years in 2014, and during this period of time the age of fatherhood has also increased [9]. The prevalence of clomiphene use has also increased two-fold from 2001 to 2014, which is perhaps not surprising in light of a recent meta-analysis showing declining sperm counts over the past four decades [10]. Indeed, clomiphene is the most common medical treatment offered for male infertility [8]. It is unclear whether this is because more physicians are comfortable with prescribing clomiphene for infertility or because clomiphene is being prescribed increasingly for causes other than idiopathic male infertility, such as hypogonadal symptoms.

While male infertility is the most common associated diagnosis in this study, a sizeable proportion of men received clomiphene with an associated diagnosis of "testicular hypofunction." This is supported in the literature, with multiple studies showing a significant rise in testosterone levels with clomiphene usage [11]. In a cohort of 46 patients with 3 years follow-up, Moskovic et al [12] demonstrated continued efficacy and safety of clomiphene in the management of hypogonadism. In addition, Ramasamy et al [13] found that hypogonadal men who received clomiphene citrate and testosterone gels had similar relief of symptoms.

There is variability in relevant laboratory testing accompanying the use of clomiphene. Only $43.7 \%$ of men who used clomiphene received a semen analysis, despite American Urological Association best practice recommendation that infertile men receive two semen analyses as part of a baseline infertility evaluation prior to initiating treatment [14]. Moreover, prior to initiating a hormonal regulator such as clomiphene it is customary to evaluate the hypothalamic-pituitarygonadal axis; only $23.5 \%$ of men who used clomiphene in this study had a testosterone level checked, and an even smaller proportion had pituitary hormones evaluated. While men being treated primarily for hypogonadism would not require a semen analysis, this is unlikely to account wholly for the low percentage of men receiving semen testing. These findings suggest a need to promote greater awareness for guideline-based treatment of male infertility, and underscore the importance of involving andrology specialists to provide a more comprehensive evaluation. Indeed, it has been noted that $25 \%$ of urologists may prescribe testosterone for the indication of infertility, despite its known side effect of reducing spermatogenesis [8].

Another finding of interest is that the median length of clomiphene use within this cohort was only 3.6 months. Ross et al [15] found that approximately $66 \%$ of patients on clomiphene had a semen parameter that responded by 3 months, but that the remainder required 6 to 15 months. It is unclear why the men in this cohort discontinued clomiphene therapy so early, but possible reasons include a lack of perceived efficacy, intolerance of side effects, achievement of pregnancy, or elective use of assisted reproduction. 
Importantly, the results from this study indicate a low rate of side effects due to clomiphene use in men. Specifically, clomiphene use does not appear to be associated with an increased rate of thrombotic events, vision problems, liver disease, or nausea. Furthermore, clomiphene use in this study showed decreased rates of gynecomastia, mental disorders, skin disorders, and hypertension; however it is important to note that the event rate for these side effects was low and it would be premature to suggest clomiphene as a treatment for such conditions. Overall, our study reinforces the conclusion of the Moskovic study [12] that demonstrated good long-term efficacy and safety of clomiphene use in men.

A major strength of this study is the large size of the national database from which the cohort is derived. Over 12,000 men who used clomiphene were identified over a 14-year period. For a generic medication that is used for non-FDA-approved indication, it would be difficult to support a RCT. Thus, a retrospective study involving a large volume of patients can be uniquely informative. The longitudinal collection of data additionally facilitates the observation of chronological trends in clomiphene usage.

This study is subject to limitations. First, while the MarketScan Database is a large and nationally representative, it encompasses only those services rendered via insurance claims, and does not reflect selfpay services (such as some medications obtained from compounding pharmacies). In the US, there is variable coverage for male infertility services [16,17]. As a result, the patterns of diagnostic testing and prescriptions for the self-pay population may not be reflected by this study. Second, this study relies on the accuracy of coding and claims data. While there is financial incentive for physicians to code completely and comprehensively, this may not occur for all patient encounters and may impact the associated diagnoses and laboratory testing. A third limitation is the lack of detailed prescribing information in the MarketScan Database. For example, because the optimal dosage schedule for clomiphene has not been established, and prescribers vary in their dosing regimens. Finally, the database does not list the reason for discontinuation of clomiphene or indicate whether infertile male patients prescribed clomiphene achieved the primary goal of clinical pregnancy.

\section{CONCLUSIONS}

This study demonstrates a rising prevalence and no associated adverse events in the usage of clomiphene for the treatment of male infertility in a large contemporary US cohort. The variability in associated diagnoses, diagnostic testing, and duration of treatment suggests a need for greater awareness of the proper evaluation and treatment of the infertile male with this medication.

\section{Conflicts of Interest}

The authors have nothing to disclose.

\section{Author Contribution}

Conceptualization: DPG, DVZ, LCB, MLE. Data curation: DPG, DVZ, SL. Formal analysis: DPG, DVZ, SL, MLE. Investigation: DPG, DVZ, MLE. Methodology: MLE, LCB. Project administration: DPG, DVZ. Resources: MLE. Software: DPG, DVZ, SL, MLE. Supervision: MLE, LCB. Validation: DPG, DVZ. Visualization: DPG, DVZ, MLE. Writing-original draft: DPG, DVZ. Writing-review \& editing: MLE, LCB, SL.

\section{REFERENCES}

1. Sabanegh E, Agarwal A. Male infertility. In: Wein A, Kavoussi L, Novick A, Partin A, Peters CA, editors. Campbell-Walsh urology. 9th ed. Philadelphia: Saunders Elsevier; 2007.

2. Paulson DF, Wacksman J. Clomiphene citrate in the management of male infertility. J Urol 1976;115:73-6.

3. Roth LW, Ryan AR, Meacham RB. Clomiphene citrate in the management of male infertility. Semin Reprod Med 2013;31: 245-50.

4. Practice Committee of the American Society for Reproductive Medicine. Use of clomiphene citrate in infertile women: a committee opinion. Fertil Steril 2013;100:341-8.

5. World Health Organization: Special Programme of Research, Development and Research Training in Human Reproduction; Task Force on the Prevention and Management of Infertility. A double-blind trial of clomiphene citrate for the treatment of idiopathic male infertility. World Health Organization. Int J Androl 1992;15:299-307.

6. Ghanem H, Shaeer O, El-Segini A. Combination clomiphene citrate and antioxidant therapy for idiopathic male infertility: a randomized controlled trial. Fertil Steril 2010;93:2232-5.

7. Chua ME, Escusa KG, Luna S, Tapia LC, Dofitas B, Morales M. 


\section{MEN's HEALTH}

Revisiting oestrogen antagonists (clomiphene or tamoxifen) as medical empiric therapy for idiopathic male infertility: a meta-analysis. Andrology 2013;1:749-57.

8. Ko EY, Siddiqi K, Brannigan RE, Sabanegh ES Jr. Empirical medical therapy for idiopathic male infertility: a survey of the American Urological Association. J Urol 2012;187:973-8.

9. Khandwala YS, Zhang CA, Lu Y, Eisenberg ML. The age of fathers in the USA is rising: an analysis of 168867480 births from 1972 to 2015. Hum Reprod 2017;32:2110-6.

10. Levine H, Jørgensen N, Martino-Andrade A, Mendiola J, Weksler-Derri D, Mindlis I, et al. Temporal trends in sperm count: a systematic review and meta-regression analysis. Hum Reprod Update 2017;23:646-59.

11. Lo EM, Rodriguez KM, Pastuszak AW, Khera M. Alternatives to testosterone therapy: a review. Sex Med Rev 2018;6:106-13.

12. Moskovic DJ, Katz DJ, Akhavan A, Park K, Mulhall JP. Clomiphene citrate is safe and effective for long-term management
David Guo, et al: Usage and Safety of Clomiphene by Men

of hypogonadism. BJU Int 2012;110:1524-8.

13. Ramasamy R, Scovell JM, Kovac JR, Lipshultz LI. Testosterone supplementation versus clomiphene citrate for hypogonadism: an age matched comparison of satisfaction and efficacy. J Urol 2014;192:875-9.

14. Jarow JP, Sharlip ID, Belker AM, Lipshultz LI, Sigman M, Thomas AJ, et al; Male Infertility Best Practice Policy Committee of the American Urological Association Inc. Best practice policies for male infertility. J Urol 2002;167:2138-44.

15. Ross LS, Kandel GL, Prinz LM, Auletta F. Clomiphene treatment of the idiopathic hypofertile male: high-dose, alternateday therapy. Fertil Steril 1980;33:618-23.

16. Dupree JM. Insurance coverage for male infertility care in the United States. Asian J Androl 2016;18:339-41.

17. Dupree JM, Dickey RM, Lipshultz LI. Inequity between male and female coverage in state infertility laws. Fertil Steril 2016; 105:1519-22. 